\title{
DESEMPENHO, MICROBIOTA INTESTINAL E PESO DE ÓRGÃOS DE LEITÕES NA FASE INICIAL RECEBENDO RAÇÕES COM SIMBIÓTICO E PROBIOTICO ${ }^{1}$
}

\author{
Performance, intestinal microorganisms and organs weight of piglets in the \\ initial phase receiving diets with simbiotic and probiotic ${ }^{1}$
}

\author{
Paulo Cesar Pozza², Magali Soares dos Santos Pozza ${ }^{3}$, Ricardo Vianna Nunes ${ }^{3}$, \\ Tiago Júnior Pasquetti ${ }^{3}$, Iderson Venturi ${ }^{4}$, Marli Busanello ${ }^{3}$
}

\begin{abstract}
RESUMO
Neste Trabalho, objetivou-se avaliar o efeito da suplementação de dietas contendo probiótico e simbiótico sobre o desempenho de leitões dos 21 aos 49 dias, microbiota intestinal e peso dos órgãos. Foram utilizados 120 leitões mestiços desmamados aos 21 dias de idade, distribuídos em um delineamento de blocos casualizados, com três tratamentos (antibiótico, probiótico e simbiótico) e cinco repetições, sendo a unidade experimental representada pela baia, onde foram alojados oito leitões. No período de 21 a 35 dias de idade, não se observou diferença $(\mathrm{P}>0,05)$ no desempenho. No período de 36 até os 49 dias, pode-se observar maior ganho diário de peso $(\mathrm{P}<0,01)$ para o tratamento contendo antibiótico. Foi observada uma maior contagem de bactérias lácticas $(\mathrm{P}<0,05)$ no conteúdo do cólon, aos 35 dias de idade para o tratamento contendo probiótico. Os pesos relativos dos órgãos não foram influenciados $(\mathrm{P}>0,05)$ pelos tratamentos. O uso de probiótico e simbiótico nas rações foi efetivo para leitões dos 21 aos 35 dias de idade para as variáveis de desempenho e contagem de coliformes no íleo e cólon, e dos 36 aos 49 dias de idade o uso de antibiótico foi melhor em relação as variáveis de desempenho.
\end{abstract}

Termos para indexação: Inulina, ganho de peso, suínos, enterobactérias, lactobacilos.

\section{ABSTRACT}

The objective of this study was to evaluate the effect of diets containing probiotic and simbiotic on the performance of piglets from 21 to 49 days, intestinal microorganisms and weight of organs. In this study there were used 120 crossbred piglets, weaned at 21 days of age, alloted in randomized blocks design, with three treatments (antibiotic, probiotic and simbiotic) and five replicates, being the experimental unit represented by the pen, where eight piglets were hosted. In the period from 21 to 35 days of age no difference was observed $(\mathrm{P}>0.05)$ for the performance results. In the period from 36 to 49 days could be observed a higher daily weight gain $(\mathrm{P}<0.01)$ for the antibiotic treatment. A higher count of lactic bacteria was observed $(\mathrm{P}<0.05)$ in the colon content, in piglets with 35 days of age, for the probiotic treatment. The relative organs weight was not influenced $(\mathrm{P}>0.05)$ by the treatments. The use of probiotic and simbiotic in the diets was effective for piglets from 21 to 35 days of age for performance and coliform count in the ileum and large gut, and from 36 to 49 days of age the use of antibiotic in the diet was better for the performance parameters.

Index terms: Inulin, weight gain, swine, enterobacteria, lactobacillus.

(Recebido em 1 de novembro de 2007 e aprovado em 6 de maio de 2009)

\section{INTRODUÇÃO}

Os leitões, após o desmame, geralmente sofrem de diarréia seguida de redução no crescimento e aumento na mortalidade. Entretanto, os antibióticos têm sido tradicionalmente adicionados na dieta como promotores de crescimento, mas, em razão da resistência bacteriana à antibióticos e segurança alimentar, essa prática tem se tornado menos aceitável, o que tem levado à restrição do seu uso, sendo banido em alguns países.

Outra preocupação é quanto à produção de suínos orgânicos e segundo as diretrizes do Instituto
Biodinâmico - IBD (2000), toda a ração adquirida para este tipo de criação, deverá ser livre de antibióticos, sendo permitido o uso de leveduras como aditivos para arraçoamento animal.

Os probióticos podem ser uma alternativa ao uso de antibióticos como promotores de crescimento nas rações, uma vez que não proporcionam resistência aos microrganismos patogênicos e não deixam resíduos indesejáveis ao consumo humano.

O período de desmame é um dos mais promissores para efeito do uso de probióticos e está relacionado com competição por exclusão com bactérias nocivas. Os

\footnotetext{
${ }^{1}$ Trabalho Financiado pela Itaipu Binacional

2Universidade Estadual do Oeste do Paraná/UNIOESTE - Rua Pernambuco - 1777 - Marechal Cândido Rondon, PR - pcpozza@yahoo.com.br

${ }^{3}$ Universidade Estadual do Oeste do Paraná/UNIOESTE - Marechal Cândido Rondon, PR

${ }^{4}$ Universidade Estadual do Oeste do Paraná/UNIOESTE - Indianópolis, PR
} 
probióticos podem ter um efeito positivo, influenciando o balanço microbiano, integridade do epitélio intestinal e maturação apropriada do intestino, associada ao tecido e função do sistema neuro-endócrino (Metzler et al., 2006).

Para que haja uma maior persistência no organismo, o microrganismo probiótico precisa se aderir ao epitélio intestinal. Assim sendo, surgiu o conceito de prebióticos, que foi definido como sendo um ingrediente alimentício não digestível que afeta beneficamente o hospedeiro por meio de um estímulo do crescimento e/ou atividade de um número limitado de bactérias no cólon (Gibson \& Roberfroid, 1995).

A adição de carboidratos fermentáveis na dieta melhora a diversidade e estabilidade da microflora no cólon. A inulina, por sua vez, é um polissacarídeo não amiláceo que consiste em cadeias de unidades de frutose unidas por ligações b $(2,1)$ e que, frequentemente, terminam com uma única molécula de glicose, ocorrendo naturalmente como carboidrato de reserva em muitas espécies de plantas. Estudos "in vitro" e "in vivo", utilizando-se animais e humanos, comprovam que a inulina pode ser considerada um prebiótico com fator bifidogênico, pois estimula seletivamente o crescimento de bactérias como Bifidobacterium, Lactobacillus e Bacteroides, em detrimento de microrganismos potencialmente patogênicos como E. coli e clostrídeos (Havenaar et al., 1999).

Loh et al. (2006) verificaram que a adição de inulina em diferentes dietas para suínos afeta significativamente a população de bifidobactérias, enquanto lactobacilos não são influenciados.

Recentemente, muitos probióticos são suplementados com prebióticos em um único produto, introduzindo-se então o conceito de simbióticos, que é o fornecimento de bactérias probióticas, principalmente lactobacilos e bifidobactérias, combinado com os prebióticos.

Neste trabalho, objetivou-se avaliar o desempenho de leitões dos 21 aos 49 dias de idade, suplementados com probióticos e inulina, assim como avaliar a contagem de microrganismos na digesta íleal e colônica, e os pesos absolutos e relativos dos órgãos, aos 35 e 49 dias de idade.

\section{MATERIAL E MÉTODOS}

O experimento foi conduzido em uma granja localizada no município de Mercedes-PR, considerada como sendo de médio desafio.

Foram utilizados 120 leitões, sendo 60 machos castrados e 60 fêmeas, desmamados aos 21 dias de idade, distribuídos em um delineamento experimental de blocos ao acaso com três tratamentos e cinco repetições, sendo a unidade experimental representada pela baia, onde foram alojados oito leitões (quatro machos castrados e quatro fêmeas).

Ao $21^{\circ}$ dia, os animais foram desmamados e pesados, sendo alojados em baias de creche convencionais, localizadas em prédio de alvenaria, dotadas de comedouros de alvenaria e de bebedouros tipo chupeta. No interior das instalações, foi instalado um termômetro digital para realização das leituras diárias das temperaturas mínimas e máximas.

Os tratamentos foram constituídos de ração com antibióticos e sem a mistura simbiótica (CONTROLE); ração sem antibióticos, contendo somente o probiótico (PROBIÓTICO); e ração sem antibióticos, contendo probióticos e inulina (SIMBIÓTICO).

As rações utilizadas dos 21 aos 35 e dos 36 aos 49 dias de idade (Tabela 1 ) foram formuladas para atender às exigências nutricionais do National Resource Council - NRC (1998), sendo realizadas as análises de matéria seca, proteína bruta, matéria mineral, cálcio e fósforo.

O probiótico utilizado era composto por Lactobacillus acidophilus (3,5x10 $11 \mathrm{UFC} / \mathrm{kg})$, Enterococcus faecium $\left(3,5 \times 10^{11} \mathrm{UFC} / \mathrm{kg}\right)$ e Bifidobacterium bifidum $\left(3,5 \times 10^{11} \mathrm{UFC} / \mathrm{kg}\right)$.

As variáveis de desempenho avaliadas foram o peso final, consumo diário de ração, ganho diário de peso e a conversão alimentar, no período de 21 a 35 dias, 36 a 49 dias e no período total (21 a 49 dias).

Ao $35^{\circ}$ e $49^{\circ}$ dias de idade, abateu-se um animal de cada unidade experimental, utilizando como critério o peso médio. Logo em seguida, procedeu-se a coleta das amostras de digesta do final do íleo e cólon, realizando-se imediatamente a leitura do $\mathrm{pH}$.

As amostras foram coletadas e acondicionadas em recipientes esterilizados e imediatamente transportadas ao Laboratório de Microbiologia da UNIOESTE. Essas amostras foram preparadas e diluídas, adicionando um grama de fezes em $99 \mathrm{ml}$ de solução-tampão fosfato $\mathrm{pH}$ 7,2; obtendo-se uma diluição inicial de 1:100, sendo, posteriormente, realizadas diluições sucessivas, onde se procedeu o plaqueamento nos meios específicos.

Para a avaliação da flora acidolática foi utilizado o ágar para lactobacilos MRS (De Man, Rogosa e Sharpe) e para coliformes o VRB (Violet Red Bile Agar).

Foram também pesados o fígado, rins, coração, pulmão e baço. De posse do peso absoluto dos órgãos e do peso da carcaça, foram determinados os pesos relativos dos órgãos. 
Tabela 1 - Composição centesimal das rações experimentais.

\begin{tabular}{|c|c|c|c|c|c|c|}
\hline \multirow{2}{*}{ Ingredientes } & \multicolumn{3}{|c|}{ 21-35 dias } & \multicolumn{3}{|c|}{ 36-49 dias } \\
\hline & Controle & Probiótico & Simbiótico & Controle & Probiótico & Simbiótico \\
\hline Milho & 42,32 & 42,32 & 42,32 & 55,72 & 55,72 & 55,72 \\
\hline Farelo de soja & 20,00 & 20,00 & 20,00 & 23,45 & 23,45 & 23,45 \\
\hline Produto lácteo $^{1}$ & 15,00 & 15,00 & 15,00 & - & - & - \\
\hline Soro de leite em pó & - & - & - & 6,00 & 6,00 & 6,00 \\
\hline Farinha de peixe & 5,00 & 5,00 & 5,00 & 4,00 & 4,00 & 4,00 \\
\hline Glúten de milho & 5,00 & 5,00 & 5,00 & 4,00 & 4,00 & 4,00 \\
\hline Óleo vegetal & 1,87 & 1,87 & 1,87 & 0,87 & 0,87 & 0,87 \\
\hline Açúcar & 3,00 & 3,00 & 3,00 & 3,00 & 3,00 & 3,00 \\
\hline Calcário & 0,80 & 0,80 & 0,80 & 0,71 & 0,71 & 0,71 \\
\hline Fosfato bicálcico & 0,34 & 0,34 & 0,34 & 0,49 & 0,49 & 0,49 \\
\hline Cloreto de colina & 0,20 & 0,20 & 0,20 & 0,20 & 0,20 & 0,20 \\
\hline DL- Metionina & 0,01 & 0,01 & 0,01 & - & - & - \\
\hline L-Lisina HCL & 0,10 & 0,10 & 0,10 & 0,11 & 0,11 & 0,11 \\
\hline Sal & 0,20 & 0,20 & 0,20 & 0,17 & 0,17 & 0,17 \\
\hline Antioxidante $^{2}$ & 0,01 & 0,01 & 0,01 & 0,01 & 0,01 & 0,01 \\
\hline Ácidos orgânicos ${ }^{3}$ & 0,25 & 0,25 & 0,25 & 0,20 & 0,20 & 0,20 \\
\hline Núcleo $^{4}$ & 5,00 & 5,00 & 5,00 & - & - & - \\
\hline Mistura vitamínica $^{5}$ & - & - & - & 0,12 & 0,12 & 0,12 \\
\hline Mistura mineral $^{6}$ & - & - & - & 0,05 & 0,05 & 0,05 \\
\hline Inerte & 0,80 & 0,60 & 0,10 & 0,80 & 0,60 & 0,10 \\
\hline Antibiótico $^{7}$ & 0,10 & 0,00 & 0,00 & 0,10 & 0,00 & 0,00 \\
\hline Probiótico & 0,00 & 0,30 & 0,30 & 0,00 & 0,30 & 0,30 \\
\hline Inulina & 0,00 & 0,00 & 0,50 & 0,00 & 0,00 & 0,50 \\
\hline \multicolumn{7}{|l|}{ Composição química } \\
\hline $\mathrm{EM}(\mathrm{kcal} / \mathrm{kg})$ & 3265 & 3265 & 3353 & 3268 & 3268 & 3268 \\
\hline Matéria seca $(\%)^{8}$ & 90,09 & 90,00 & 90,02 & 88,79 & 88,79 & 88,79 \\
\hline Proteína bruta $(\%)^{8}$ & 20,56 & 20,63 & 20,49 & 18,29 & 18,24 & 18,32 \\
\hline Matéria mineral $(\%)^{8}$ & 8,08 & 7,38 & 6,73 & 4,44 & 4,31 & 4,22 \\
\hline Cálcio $(\%)^{8}$ & 0,81 & 0,83 & 0,82 & 0,88 & 0,85 & 0,86 \\
\hline Fósforo total $(\%)^{8}$ & 0,74 & 0,71 & 0,70 & 0,57 & 0,55 & 0,54 \\
\hline Fósforo disp.(\%) & 0,40 & 0,40 & 0,40 & 0,32 & 0,32 & 0,32 \\
\hline Lisina dig. (\%) & 1,19 & 1,19 & 1,19 & 1,01 & 1,01 & 1,01 \\
\hline Met.+Cis. dig. (\%) & 0,69 & 0,69 & 0,69 & 0,63 & 0,63 & 0,63 \\
\hline Treonina dig. (\%) & 0,77 & 0,77 & 0,77 & 0,70 & 0,70 & 0,70 \\
\hline Triptofano dig. (\%) & 0,22 & 0,22 & 0,22 & 0,20 & 0,20 & 0,20 \\
\hline
\end{tabular}

${ }^{1}$ Nuklospray. ${ }^{2}$ BHT. ${ }^{3}$ Ácidos propiônico, fórmico e lático. ${ }^{4}$ Contendo: Cálcio $(0,78 \%)$, fósforo disponível $(0,68)$, lisina digestível $(1,45 \%)$, zinco $(0,27 \%)$, lactose $(30 \%)$, mistura mineral e vitamínica, veículo qsp, sem antibióticos promotores de crescimento. ${ }^{5}$ Vit. A (8.000.000 UI); Vit. D3 (1.200.000 UI); Vit. E (20.000mg); Vit K3 (2500mg); Tiamina (1000mg); Riboflavina (4000mg); Vit B12 (20mg), Niacina (25000mg); Ácido Pantotênico (10.000mg); Biotina (50g); Ácido Fólico (600mg); Vit. C (50.000 mg), Antioxidante (125mg). ${ }^{6} \mathrm{Zn}$ (80000mg); Fe (70000mg); Mn (40000mg); Cu (20000mg), I (800mg); Co (500mg); Se (500mg), Veículo qsp (1000g). ${ }^{7}$ Princípio ativo: Colistina e Gentamicina. ${ }^{8}$ Valores analisados. 
Os resultados de desempenho, pesos absolutos e relativos dos órgãos e contagem microbiana na digesta foram submetidos às análises estatísticas, utilizando-se o sistema de análises estatísticas e genéticas SAEG (Universidade Federal de Viçosa - UFV, 1999), e como procedimento estatístico utilizou-se o teste de comparação de médias Student Newman Keuls.

\section{RESULTADOS E DISCUSSÃO}

As temperaturas, mínima $\left(21,03 \pm 1,38^{\circ} \mathrm{C}\right)$ e máxima $(29,89 \pm 2,98)$, registradas no interior da sala de creche, podem ser consideradas como acima da zona de termoneutralidade, principalmente a temperatura máxima, pois Hannas (1999) relatou que as temperaturas mínima e máxima ideais, para leitões com quatro semanas de vida, são de 21 e $22^{\circ} \mathrm{C}$, respectivamente; e para leitões de cinco a oito semanas esses valores seriam de 20 e $22^{\circ} \mathrm{C}$, respectivamente.

No período de 21 a 35 dias de idade não foram observadas diferenças $(\mathrm{P}>0,05)$ nos resultados de ganho diário de peso, consumo diário de ração e na conversão alimentar (Tabela 2), o que pode ser considerado um resultado positivo, uma vez que o período pós desmame é caracterizado como uma fase de transição e, em muitos casos, observam-se casos de diarréia, decorrentes de vários fatores estressantes.

Resultados semelhantes foram obtidos por Sanches et al. (2006) quando, avaliando a utilização de probiótico contendo Bacillus subtilis, prebiótico (mananoligossacarideo) e simbiótico, sobre o desempenho de leitões desmamados aos 23 de idade, verificaram que os dados de desempenho não diferiram daqueles que receberam ração contendo olaquindox. Da mesma forma, Santos et al. (2003), avaliando quatro níveis de prebiótico (manose), para leitões desmamados aos 21 dias de idade, não observaram diferenças entre os tratamentos sobre os resultados de desempenho no período de creche, sendo a colistina utilizada como antibiótico.

No entanto, no período de 36 até os 49 dias, observouse um maior ganho diário de peso $(\mathrm{P}<0,01)$ para o tratamento controle (Tabela 2) em relação aos demais, o que influenciou de forma direta o peso médio aos 49 dias de idade $(\mathrm{P}<0,01)$, apresentando melhores resultados o tratamento controle. A conversão alimentar foi semelhante $(\mathrm{P}>0,05)$ entre o controle e o probiótico, o mesmo ocorrendo entre o probiótico e o simbiótico, porém este último apresentou um pior resultado de conversão alimentar $(\mathrm{P}<0,05)$ em relação ao controle.

Tabela 2 - Desempenho de leitões dos 21 aos 35, 36 aos 49 e dos 21 aos 49 dias de idade submetidos aos tratamentos.

\begin{tabular}{|c|c|c|c|c|}
\hline & \multicolumn{3}{|c|}{ Tratamento } & \multirow[b]{2}{*}{$\mathrm{CV}(\%)$} \\
\hline & Controle & Probiótico & Simbiótico & \\
\hline Peso Médio Inicial (kg) & 6,46 & 6,45 & 6,45 & \\
\hline Peso Médio aos 35 dias (kg) & 8,37 & 8,40 & 8,14 & 2,85 \\
\hline Peso Médio aos 49 dias $(\mathrm{kg})^{1}$ & $14,12^{\mathrm{a}}$ & $12,88^{\mathrm{b}}$ & $12,18^{\mathrm{b}}$ & 4,84 \\
\hline \multicolumn{5}{|l|}{ Consumo Diário de Ração (g) } \\
\hline 21 a 35 dias & 237,75 & 240,00 & 224,00 & 6,61 \\
\hline 36 a $49 \operatorname{dias}^{1}$ & $620,00^{\mathrm{a}}$ & $501,50^{\mathrm{b}}$ & $528,25^{\mathrm{b}}$ & 4,35 \\
\hline 21 a $49 \operatorname{dias}^{1}$ & $428,88^{\mathrm{a}}$ & $370,75^{\mathrm{b}}$ & $376,13^{\mathrm{b}}$ & 3,69 \\
\hline \multicolumn{5}{|l|}{ Ganho Diário de Peso (g) } \\
\hline 21 a 35 dias & 136,75 & 138,75 & 121,00 & 13,23 \\
\hline 36 a 49 dias $^{1}$ & $408,50^{\mathrm{a}}$ & $319,00^{\mathrm{b}}$ & $288,00^{\mathrm{b}}$ & 9,76 \\
\hline 21 a $49 \operatorname{dias}^{1}$ & $272,63^{\mathrm{a}}$ & $228,88^{b}$ & $204,50^{\mathrm{b}}$ & 9,51 \\
\hline \multicolumn{5}{|l|}{ Conversão Alimentar (g/g) } \\
\hline 21 a 35 dias & 1,74 & 1,79 & 1,88 & 9,69 \\
\hline 36 a $49 \operatorname{dias}^{2}$ & $1,52^{\mathrm{a}}$ & $1,59^{\mathrm{ab}}$ & $1,84^{\mathrm{b}}$ & 10,94 \\
\hline 21 a $49 \operatorname{dias}^{2}$ & $1,57^{\mathrm{a}}$ & $1,64^{\mathrm{b}}$ & $1,85^{\mathrm{b}}$ & 8,34 \\
\hline
\end{tabular}

${ }^{1}$ Médias seguidas de letras diferentes, na mesma linha, diferem entre si pelo teste de Student Newman Keuls, em nível de $1 \%$ de probabilidade.

${ }^{2}$ Médias seguidas de letras diferentes, na mesma linha, diferem entre si pelo teste de Student Newman Keuls, em nível de 5\% de probabilidade. 
Os melhores resultados de ganho diário de peso para o tratamento controle, dos 36 aos 49 dias de idade, foi acompanhado por um maior consumo diário de ração em relação aos demais tratamentos, refletindo na resposta da conversão alimentar para a fase em questão.

As respostas biológicas na nutrição animal, quanto à utilização de prebióticos, nem sempre são evidenciadas, o que pode estar relacionado com a composição química dos demais ingredientes da dieta, com a dosagem adicionada, com a adaptação e a seletividade da microbiota ao prebiótico, ou ao nível de estresse do animal (Silva \& Nornberg, 2003).

O resultado de desempenho, dos 36 aos 49 dias de idade, influenciou o resultado no período total (21 aos 49 dias de idade), uma vez que os resultados foram semelhantes no período de 21 à 35 dias de idade.

Aos 35 dias de idade, observou-se maior contagem de bactérias lácticas $(\mathrm{P}<0,05)$ no conteúdo do cólon (Tabela 3 ) para o tratamento contendo probiótico em relação ao tratamento simbiótico, o qual apresentou uma semelhança nas contagens de bactérias lácticas em relação ao controle que, por sua vez, foi semelhante ao probiótico. As contagens de bactérias lácticas, aos 49 dias de idade (Tabela 3), foram maior na digesta ileal para os tratamentos controle e simbiótico em relação ao tratamento probiótico.

As contagens de bactérias lácticas em meio MRS no cólon, aos 35 e 49 dias de idade, assemelham-se aos valores apresentados por Mikkelsen \& Jensen (2004), que obteve valores (em logarítimos) de 8,73; 9,01 e 9,35 UFC/g, para os tratamentos controle negativo, antibiótico e probiótico, respectivamente. No entanto, esses valores foram obtidos nas fezes de leitões aos 28 dias de idade.

As contagens de coliformes totais aos 35 e 49 dias de idade foram semelhantes entre os tratamentos avaliados $(\mathrm{P}>0,05)$, podendo-se inferir que, para essa variável, os tratamentos proporcionaram o mesmo efeito.

Tabela 3 - Avaliação do pH e logaritmos das médias do número de unidades formadoras de colônias (UFC/g) de lactobacilos (MRS) e contagem de coliformes totais (VRB), por grama de digesta do íleo e do cólon, de leitões aos 35 e 49 dias de idade, submetidos aos tratamentos.

\begin{tabular}{|c|c|c|c|c|}
\hline & \multicolumn{3}{|c|}{ Tratamento } & \multirow[b]{2}{*}{$\mathrm{CV}(\%$} \\
\hline & Controle & Probiótico & Simbiótico & \\
\hline \multicolumn{5}{|c|}{35 dias de idade } \\
\hline \multicolumn{5}{|c|}{ Íleo } \\
\hline MRS (Bac. Lacticas) & 7,97 & 8,40 & 7,72 & 5,58 \\
\hline VRB (Coliformes) & 5,85 & 5,90 & 5,02 & 15,30 \\
\hline $\mathrm{pH}$ & 6,85 & 6,49 & 6,59 & 3,84 \\
\hline \multicolumn{5}{|c|}{ Cólon } \\
\hline MRS (Bac. Lacticas) & $8,76^{\mathrm{ab}}$ & $9,05^{\mathrm{a}}$ & $8,22^{\mathrm{b}}$ & 5,00 \\
\hline VRB (Coliformes) & 5,04 & 5,56 & 5,17 & 9,81 \\
\hline $\mathrm{pH}$ & 6,65 & 6,54 & 6,37 & 3,71 \\
\hline \multicolumn{5}{|c|}{49 dias de idade } \\
\hline \multicolumn{5}{|c|}{ Íleo } \\
\hline MRS (Bac. Lacticas) & $8,59^{\mathrm{a}}$ & $7,88^{\mathrm{b}}$ & $8,56^{\mathrm{a}}$ & 4,32 \\
\hline VRB (Coliformes) & 5,50 & 6,62 & 5,92 & 13,42 \\
\hline $\mathrm{pH}$ & 6,11 & 6,72 & 6,14 & 6,24 \\
\hline \multicolumn{5}{|c|}{ Cólon } \\
\hline MRS (Bac. Lacticas) & 9,25 & 9,17 & 9,05 & 1,93 \\
\hline VRB (Coliformes) & 6,32 & 6,66 & 6,72 & 11,61 \\
\hline $\mathrm{pH}$ & 6,34 & 5,99 & 6,31 & 7,58 \\
\hline
\end{tabular}

Médias seguidas de letras diferentes, na mesma linha, diferem entre si pelo teste de Student Newman Keuls, em nível de 5\% de probabilidade. 
Bogonc Matijasik et al. (2004), avaliando o fornecimento do probiótico contendo cepas de L. gasseri K7 e LF 221 para leitões, concluíram que a diferença nas contagens de lactobacilos e coliformes pode ser mais atribuída às variações normais entre os animais do que ao tratamento probiótico em si.

A utilização de inulina pelas bactérias lácticas, ocorreu ao final do íleo (Tabela 3), observando-se, ainda, que essa utilização é um processo que demandou tempo, uma vez que, aos 35 dias de idade, o simbiótico mostrou um resultado inferior ao probiótico no cólon e, aos 49 dias de idade, apresentou melhores contagens. $\mathrm{O}$ aumento na população de lactobacilos, decorrente do fornecimento de simbiótico para leitões desmamados, foi constatado por Nemcova (1999), que forneceu FOS (3 gr/dia) em combinação com cepa probiótica de Lactobacillus paracasei.

Avaliando a utilização de 5\% de frutoligossacarideo (FOS) em dietas para leitões recém desmamados, Santos et al. (2003) observaram uma ação desses compostos na população de bifidobactérias $(8,64)$ no cólon proximal, e redução na população de Escherichia coli para animais suplementados com FOS $(5,05)$ e polpa de beterraba $(5,01)$, sendo esses valores próximos aos obtidos no presente trabalho. Esse efeito também foi verificado na porção distal do cólon, onde a contagem deste microrganismo para animais que receberam FOS foi reduzida $(4,78)$, entretanto, os animais tratados com polpa de beterraba obtiveram os menores níveis $(3,95)$.
Segundo Mosenthin \& Bauer (2000), outras explicações para as diferentes respostas, obtidas na utilizacão de compostos de potencial ação prebiótica, podem estar relacionadas com a presença de bactérias degradadoras dos compostos testados como prebióticos nos diferentes compartimentos do trato gastrointestinal.

Não foram observadas diferenças significativas para os valores de $\mathrm{pH}$ na digesta do íleo e cólon aos 35 e 49 dias de idade. Por outro lado, Mikkelsen et al. (2003), avaliando o efeito da inclusão de FOS e transgalactossacarídeos (TOS) para leitões aos 28 dias, observaram maiores valores de pH no conteúdo do cólon dos animais que receberam FOS $(6,13)$ e TOS $(6,28)$, quando comparadas à dieta controle $(6,00)$, e às contagens de anaeróbios totais, lactobacilos e enterobactérias não foram influenciadas.

De acordo com Blanchard (2000), a faixa ótima para o crescimento de E. coli está entre 4,3 e 9,5; para Salmonella sp. está entre 4,0 e 9,0 e, para Lactobacillus $S P$, entre 3,8 e 7,2 . O menor $\mathrm{pH}$ é importante para o menor crescimento de bactérias patogênicas como E. coli e Salmonella, pois elas não são capazes de sobreviver ao $\mathrm{pH}$ ácido, ao contrário das bactérias não patogênicas.

Não foram observadas diferenças $(\mathrm{P}>0,05)$ para o peso relativo dos órgãos, sendo que o peso relativo do fígado variou de 3,61 a 3,98\%; dos 21 aos 35 dias de idade; e de 3,82 a 4,11\%, dos 36 aos 49 dias de idade (Tabelas 4 e 5), sendo maiores em relação aos obtidos por Ferreira et al. (2003), que obteve uma variação de 3,42 a 3,69\% para animais com $30 \mathrm{~kg}$ de peso vivo.

Tabela 4 - Pesos absolutos e relativos dos órgãos de leitões aos 35 dias de idade.

\begin{tabular}{lcccc}
\hline & & Tratamento & & \\
\hline & Controle & Probiótico & Simbiótico & CV $(\%)$ \\
\hline Peso Absoluto $(\mathrm{g})$ & & & & 11,41 \\
\hline Fígado & 215,34 & 218,96 & 226,79 & 9,32 \\
Rins & 42,64 & 45,26 & 42,92 & 3,84 \\
Coração & 40,16 & 39,53 & 40,48 & 5,73 \\
Pulmão & $83,13^{\mathrm{a}}$ & $85,03^{\mathrm{a}}$ & $92,52^{\mathrm{b}}$ & 13,12 \\
Baço & 12,30 & 13,28 & 14,07 & 12,37 \\
\hline Peso Relativo (\%) & & & 3,98 & 6,94 \\
\hline Fígado & 3,72 & 3,61 & 0,75 & 7,26 \\
Rins & 0,73 & 0,75 & 0,50 & 9,66 \\
Coração & 0,48 & 0,47 & 1,63 & 11,48 \\
Pulmão & 1,43 & 1,41 & 0,25 & \\
Baço & 0,21 & 0,22 & & \\
\hline Méas seguidas & & & \\
\hline
\end{tabular}

Médias seguidas de letras diferentes, na mesma linha, diferem entre si pelo teste de Student Newman Keuls, em nível de 5\% de probabilidade. 
Tabela 5 - Pesos absolutos e relativos dos órgãos de leitões aos 49 dias de idade.

\begin{tabular}{lcccc}
\hline & & Tratamento & & \\
& Controle & Probiótico & Simbiótico & CV(\%) \\
\hline Peso Absoluto (g) & & & & \\
\hline Fígado & 409,42 & 419,12 & 353,04 & 11,72 \\
Rins & 77,80 & 73,13 & 73,39 & 16,39 \\
Coração & 63,40 & 65,86 & 57,40 & 10,02 \\
Pulmão & 147,84 & 152,33 & 132,26 & 9,99 \\
Baço & 17,60 & 23,00 & 19,99 & 14,92 \\
\hline Peso Relativo (\%) & & & 3,82 & \\
\hline Fígado & 3,88 & 4,11 & 0,81 & 20,74 \\
Rins & 0,74 & 0,71 & 0,63 & 4,33 \\
Coração & 0,61 & 0,64 & 1,45 & 6,32 \\
Pulmão & 1,42 & 1,52 & 0,22 & 17,39 \\
Baço & 0,17 & 0,22 & & \\
\hline
\end{tabular}

Santos et al. (2003) também verificaram que os pesos absolutos e relativos do fígado e pâncreas, não foram influenciados pela adição de manose na ração. Segundo Rao \& Mc Cracken (1992), os pesos dos órgãos variam com o consumo de energia e/ou proteína, sugerindo que, mantidas as mesmas quantidades, os pesos serão semelhantes.

\section{CONCLUSÕES}

O uso de probiótico e simbiótico nas rações foi efetivo para leitões dos 21 aos 35 dias de idade para as variáveis de desempenho e contagem de coliformes no íleo e cólon, e dos 36 aos 49 dias de idade, o uso de antibiótico foi melhor em relação às variáveis de desempenho.

\section{REFERÊNCIAS BIBLIOGRÁFICAS}

BLANCHARD, P. Less buffering, more enzymes and organic acids. [S.1]: Feed Mix, 2000.

BOGONC MATIJASIC, B.; STOJKOVIC, S.; SALOBIR, J.; MALOVRH, S.; ROGELJ, I. Evaluation of the Lactobacillus gasseri K7 and LF 221 strains in weaned piglets for the possible probiotic use and their detection in the faeces. Animal Research, Les Ulis, v.53, p.35-44, 2004.

FERREIRA, R.A.; OLIVEIRA, R.F.M.; DONZELE, J.L.; LOPES, D.C.; ORLANDO, U.A.D.; RESENDE, W.O.;
VAZ, R.G.M.V. Redução da proteína bruta da ração para suínos machos castrados dos 15 aos $30 \mathrm{~kg}$ mantidos em termoneutralidade. Revista Brasileira de Zootecnia, Viçosa, v.32, n.6, p.1639-1646, 2003. Suplemento.

GIBSON, G.R.; ROBERFROID, M.B. Dietary modulation of the humam colonic microbiota: introducing the concept of prebiotics. Journal of Nutrition, Bethesda, v.125, p.1401-1412, 1995.

HANNAS, M.I. Aspectos fisiológicos e a produção de suínos em clima quente. In: SILVA, I.J.O. (Ed.).

Ambiência e qualidade na produção industrial de suínos. Piracicaba: FEALQ, 1999.

HAVENAAR, R.; BONNIN-MAROL, S.; DOKKUM, W. van; PETITET, S.; SCHAAFSMA, G. Inulin: fermentation and microbial ecology in the intestinal tract. Food Review International, New York, v.15, n.1, p.109-120, 1999.

INSTITUTO BIODINÂMICO. Diretrizes para o padrão de qualidade orgânico "Instituto Biodinâmico". 10. ed. Botucatu, 2000. 72p.

LOH, G.; EBERHARD, M.; BRUNNER, R.M.; HENNING, U.; KUHLA, S.; KLEESSER, B.; METGES, C.C. Inulin alters the intestinal microbiota and short-chain fatty acid concentrations in growing pigs regardless of their basal diet. Journal of Nutrition, Philadelphia, v.136, p.1198$1202,2006$. 
METZLER, B.; BAUER, E.; MONSENTH, R. Microflora management in the gastrointestinal of piglets. Journal of Animal Science, Champaign, v.18, p.1353-1362, 2006.

MIKKELSEN, L.L.; JAKBSEN, M.; JENEN, B.B. Effects of dietary oligosaccharides on microbial diversity and fructo-oligosaccharide degrading bacteria in faeces of piglets post-wealing. Animal Feed Science and Technology, Amsterdam, v.109, p.133-150, 2003.

MIKKELSEN, L.L.; JENSEN, B.B. Effect of fructooligosaccharides and transgalacto-oligosaccharides on microbial populations and microbial activity in the gastrointestinal tract of piglets post-weaning. Animal Feed Science and Technology, Amsterdam, v.117, p.107-119, 2004.

MOSENTHIN, R.; BAUER, E. The potencial use of prebiotics in pig nutrition. In: INTERNATIONAL SYMPOSIUM ON RECENTADVANCES INANIMAL NUTRITION, 2000, Seoul. Proceedings... Seoul: International University, 2000. p.515-528.
NEMCOVA, R. Study of effect of Lactobacillus paracasei and fructo-oligosscharides on faecal microflora in wealing piglets. Berliner und Munchener Tierarzhiche Wochenschrift, Berlin, v.112, p.225-228, 1999.

SANTOS, M.S.; FERREIRA, C.L.L.F.; GOMES, P.C.; SANTOS, J.L.; POZZA, P.C.; TESHIMA, E. Influência do fornecimento de probiótico à base de Lactobacillus sp. sobre a microbiota intestinal de leitões. Ciência e Agrotecnologia, Lavras, v.27, n.6, p.1395-1400, 2003.

SILVA, L.P.; NORNBERG, J.L. Prebióticos na nutrição de não ruminantes. Ciência Rural, Santa Maria, v.33, n.5, p.983-990, 2003.

UNIVERSIDADE FEDERAL DE VIÇOSA.SAEG Sistema para Análise Estatística e Genética. Viçosa, MG. 1999. 59p. 